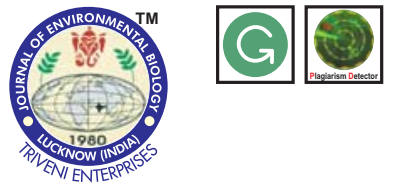

\title{
Coagulase gene polymorphism of Staphylococcus aureus in fish and its multiple drug resistant pattern
}

Authors Info

G.K. Sivaraman ${ }^{1 *}$, K.V. Lalitha ${ }^{2}$, C.N. Ravi Shankar', A.K. Jha', S. Remya', D. Vanik',

S. Visnuvinayagam ${ }^{3}$, Y. Kriplani $^{1}$ and Ajeesh ${ }^{1}$

'Department of Microbiology, Fermentation and Biotechnology, ICAR-CIFT, Veraval- 362 269, India

${ }^{2}$ Department of Microbiology, Fermentation and Biotechnology, ICAR-CIFT, Cochin- 682 029, India ${ }^{3}$ Department of Microbiology, Fermentation and Biotechnology, ICAR-MCIFT, Varshi- 400703 , India

*Corresponding Author Email : gkshivraman@gmail.com

Key words

Antibiotic resistance pattern,

Multidrug resistant,

Coagulase gene,

Staphylococci aureus

Publication Info

Paper received : 16.12 .2015

Revised received : 23.05 .2016

Re-revised received: 09.09.2016

Accepted:08.11.2016

\section{Abstract}

Aim: Staphylococcus aureus is a common inhabitant of human skin and nose of healthy people and animals. But this well-known opportunistic pathogen that can cause a broad range of infections including mild skin infections, invasive diseases, toxin mediated diseases and food poisoning. $S$. aureus is considered as one of the most frequently occurring food-borne pathogen worldwide and cause food poisoning.So the main objective of the study was to monitor the presence of multi drug resistant coagulase positive staphylococci and its coagulase gene polymorphism in fish species of retail outlets in Gujarat, India.

Methodology: S. aureus was identified using FDA, (2015) standard procedures on Baird Parker (BP) agar plates with supplements of egg yolk emulsion and potassium tellurite solution. The characteristic Staphylococci colony was purified on Tryptic Soy Agar plate and tested for coagulase with rabbit plasma. The antimicrobial sensitivity test was carried out by disc diffusion method on Mueller Hinton agar with $4 \% \mathrm{NaCl}$ and the multi drug resistant staphylococci was interpreted as per CLSI, 2014 guidelines. Polymerase Chain Reaction was carried for the detection and typing of coagulase gene polymorphism.

Results: The present investigation revealed the incidence of $11.52 \%$ coagulase positive staphylococci in fish species of retail outlets in Gujarat with Staphylococcal count of $2.0 \times 10^{1}$ to 7.8 $\mathrm{x} 10^{2} \mathrm{cfu} . \mathrm{g}^{-1}$. Almost all the CPS isolates were resistant to at least one antibiotic and many are resistant to multiple antimicrobials. The coa gene coding for coagulase protein showed multiple bands and were used for diagnosis of S.aureus.

Intrepretation: Seafood may be contaminated with multidrug resistant coagulase positive Staphylococci due to poor hygienic profile of the handlers, processing and unhygienic environment.

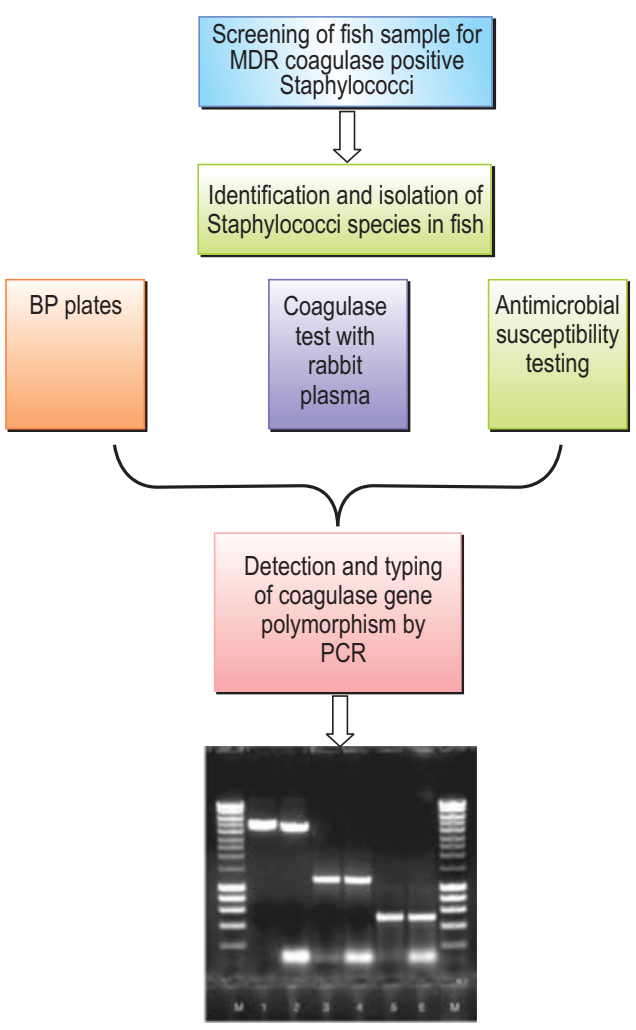




\section{Introduction}

Staphylococcus aureus is a Gram positive bacteria and commonly found on the skin surfaces and noses of $25 \%$ of healthy people and animals. It may not causes disease in healthy individuals and will cause food poisoning when eat the contaminated food products. S. aureus considered to be one of the most frequently occurring food-borne pathogen worldwide and cause food poisoning (CDC, 2010; Popovic et al., 2010). The number of outbreak and number of staphylococcal gastroenteritis is much higher than other microbial food-borne outbreak (Jay, 2000). Several studies clearly suggest the possibility of potential public health threat resulting from contamination of seafood mainly due to unhygienic handling, processing, storage and unhygienic environment. In India, the rate of staphylococcal infection is still higher because of warm and humid climate (Bhatia and Zahoor, 2007). Coagulase production by $S$. aureus is considered to be an important criterion for the safety of seafood as well as for clinical microbiologists. Though the quality and safety of food is followed mostly but food- borne outbreaks from microbial contamination, chemicals and toxins are most common in many countries today (WHO, 2007). The widespread use of antibiotics will lead to an exponential increase of antibiotic resistance in the recent years worldwide. The contamination of antibiotic resistant bacteria in food materials is the great concern to public health, as this resistance can be transferred to human (Chiu et al., 2002, Diana Gutiérrez et al., 2012). Thus, multidrugresistant $S$. aureus strains are most common in hospitalised patient and farm animals but recently reported in animal food products such as milk, meat and fishery products (Le- Loir, 2003). In view of the above, the present study was carried out to monitor the presence of multi drug resistant coagulase positive staphylococci in fish species of retail outlets in Gujarat, India.

\section{Materials and Methods}

Fish samples: A total of 408 fish samples such as Horse Mackerel, Indian Mackerel, Tuna, Ribbon fish, Seer fish, Croaker, Ghol, Dhoma, Sardine, Prawns, Shark, Ray fish, Dried fishes, Cephalopods and Surmi, etc., were collected in and around Veraval region, Gujarat during Sep, 2011 to Mar, 2015. The fish samples were collected in pre-sterilized containers, kept at $<-4^{\circ} \mathrm{C}$ in ice storage box and immediately transported to the laboratory within an hour.

Isolation and identification: S. aureus was identified using FDA, (2015) standard procedures. In brief, $10 \mathrm{~g}$ of fish samples was added to $90 \mathrm{ml}$ of sterile normal saline solution and blended in stomacher for $90 \mathrm{sec} @ 250 \mathrm{rpm}$. A serial dilution of $10^{1}$ to $10^{5}$ was made and aseptically transferred $1 \mathrm{ml}$ sample suspension of 0.3 , 0.3 and $0.4 \mathrm{ml}$ from each dilution to triplicate plates of Baird Parker agar (Oxoid, UK) containing supplements of sterile $5 \mathrm{ml}$ of $50 \%$ egg yolk emulsion and sterile $1 \mathrm{ml}$ of $1 \%$ potassium tellurite solution and incubated at $35^{\circ} \mathrm{C}$ for $48 \mathrm{hrs}$. Staphylococci showed typical colony with a circular, smooth, convex, moist, 2-3 mm diameter, grey to jet black colony with white line of margin, opaque outer zone around it (Fig. 1). From these plates, 5-6 typical colonies were streaked on to Tryptic Soy Agar plate for isolation and purification and then confirmed by Gram staining, motility, oxidase, catalase and mannitol utilization.

Coagulase test: 5-6 typical colonies of staphylococci isolated from each fish samples from Baird parker plates were selected and streaked on to TSA plates and then a well isolated colony was inoculated in Brain Heart Infusion broth (Oxoid, UK) and incubated at $25^{\circ} \mathrm{C}$ for $18-24 \mathrm{hrs}$. Coagulase tube test were carried out with $0.5 \mathrm{ml}$ of rabbit plasma with EDTA (Difco, USA) with 2 drops of $18-24 \mathrm{hrs}$ grown $\mathrm{BHI}$ broth culture, incubated at $37^{\circ} \mathrm{C}$ in serological water bath and observed every $30 \mathrm{~min}$ up to $4 \mathrm{hrs}$ for coagulation (Fig 1. B) and further confirmed with anerobic glucose fermentation and mannitol utilization (Fig 1. C).

Antibiotic sensitivity test (ABST): The antimicrobial sensitivity test to 24 antibiotics (Dodeca Staphylococci-1 and 2, HiMedia, Mumbai) were carried out by disc diffusion method (Bauers et al., 1966) on Mueller Hinton agar with $4 \% \mathrm{NaCl}$. The concentrations and resistance patterns were measured as specified by the CLSI, 2014. The list of antibiotics used with their required concentrations is listed in Table 1. Multi drug resistant (MDR) staphylococci were considered as showing resistance to penicillin along with at least three classes of antibiotics (Shittu et al., 2006). S. aureus ATCC 25923 was used as a standard positive control strain for ABST.

PCR method for detection of coa gene: DNA was extracted from putative $S$. aureus isolates by using the Bacterial Genomic DNA Kit (Sigma- Aldrich, Spain) according to the manufacturer's

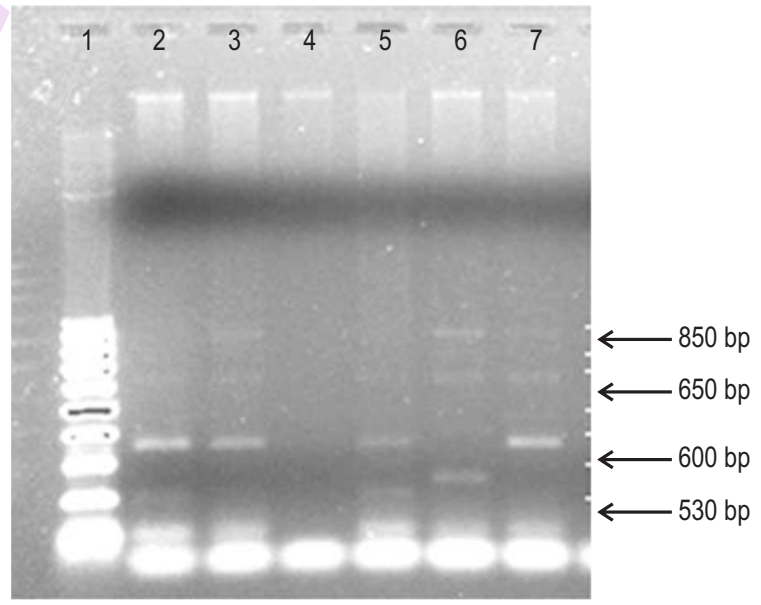

Lane 1: 100 bp DNA ladder; Lane 2-7: Coagulase positive staphylococci isolates from fish samples and amplified with different size DNAfragments

Fig. 1 : Characterization of coagulase positive Staphylococci in fish samples using PCR with Coa gene 
recommendations. The coa gene was amplified by PCR with 5 'ATAGAGATGCTGGTACAGG-3' and 5'-GCTTCCGATTGTTCG ATGC-3' primers (Hookey et al., 1998). The PCR reaction was carried out with $75 \mathrm{pM} \mathrm{\mu l}^{-1}$ of each primer, $2.5 \mu$ lo $10 \mathrm{X}$ buffer, 2.5 $\mathrm{mM}$ of $\mathrm{MgCl}^{2}, 1.5$ unit of Taq polymerase, $10 \mathrm{mM}$ of dNTP mix and $50 \mathrm{ng} \mathrm{ul}^{-1}$ of DNA to $50 \mu \mathrm{l}$ reaction volume with $92^{\circ} \mathrm{C}$ for 5 minutes followed by $92^{\circ} \mathrm{C}$ for $45 \mathrm{sec}, 55^{\circ} \mathrm{C}$ for $30 \mathrm{sec}$ and $72^{\circ} \mathrm{C}$ for $45 \mathrm{sec}$ of 35 cycles and $72^{\circ} \mathrm{C}$ for 5 minutes (Sure Cycler, Agilent, USA). The PCR products (Fig. 1) were electrophoresed on submarine electrophoresis and stained with ethidium bromide and visualized under UV light with a Gel Doc (BioRad, USA).

\section{Results and Discussion}

The present investigation revealed the incidence of coagulase positive staphylococci in fish species of retail outlets in Gujarat. A total of 235 isolates of coagulase positive staphylococci (CPS) were recovered from 408 seafood samples showing the overall incidence of $11.52 \%$. Staphylococcal count ranged between $2.0 \times 10^{1}$ to $7.8 \times 10^{2} \mathrm{cfu} \mathrm{g}^{-1}$ and exceeded the recommended limit of $100 \mathrm{cfu} \mathrm{g}^{-1}$ (ISO, 2015) in seafood. Further, $12.77 \%$ of the isolates were coagulase positive with rabbit plasma antisera. Similar to the present study, Bujjamma and Padmavathi (2015) found that an overall of $24.47 \%$ of fish samples showed the presence of S.aureus in the range of $4.16 \%$ to $50.0 \%$ in the fish market of Guntur, Andra Pradesh, India Vázquez-Sánchez et al. (2012) reported that 25\% fishery products such as fresh, frozen, salted, smoked, ready to cook, surmi, roe and ready to eat fishery products was contaminated with S.aureus in Galicia (NW Spain) retail market. Whereas Sergelidis et al. (2014) reported 7.0\% contaminate of the ready to eat fish products with S.aureus in Greece and Tulayion Elal Mus et al. (2014) also observed that $6 \%$ of the retailed fresh fish, mussel and shrimp samples were contaminated with S.aureus in Turkey. Moreover, much higher rate incidence of $S$. aureus contamination were reported for fresh (43\%) and frozen (30\%) fishery products in Spain by Vazquez-Sanchez et al. (2012) also, Ezzeldeen et al. (2011) reported S. aureus contamination low salt sardine (86.7\%), salted Mugil cephalus (93.3\%) and salted Hydrocynus froskallii (90\%) fish samples in Egypt. The difference in the prevalence rate of $S$. aureus between seafood and its products might be associated with pre-harvest and post- harvest method, storage and handling conditions (Simon and Sanjeev, 2007; Bujjamma and Padmavathi, 2015).

These coagulase positive staphylococci isolates were also assayed for susceptibility to 24 numbers of recommended antibiotics for Gram positive Staphylococci (Dodecca staphylococci 1 and 2, HiMedia, Mumbai) and showed a variable range resistant pattern to these antimicrobials tested (Table 1). Almost all of these Coagulase Positive Staphylococci isolates were resistant to penicillin with at least 3 groups of antibiotics revealing the presence of multidrug resistant (MDR) staphylocooci from these seafood samples. The antibiotic resistant pattern clearly indicated that the overall high percentage of Coagulase Positive Staphylococci isolates were $97.67 \%$

Table 1 : Antimicrobial patterns of coagulase positive beta lactam producing Staphylococci from fish species of retail outlet in Gujarat

\begin{tabular}{llll}
\hline Name of antibiotic discs & Number of isolates resistant & \% of isolates resistant & ATCC 25923 \\
\hline Penicillin $(100 \mathrm{U})$ & 29 & 96.67 & Susceptible \\
Azitrhomycin $(15 \mu \mathrm{g})$ & 29 & 96.67 & Susceptible \\
Erythromycin $(15 \mu \mathrm{g})$ & 26 & 86.67 & Susceptible \\
Clarithromycin $(15 \mu \mathrm{g})$ & 26 & 86.67 & Susceptible \\
Linezolid $(30 \mu \mathrm{g})$ & 2 & 6.67 & Susceptible \\
Co-Trimoxazole $(25 \mu \mathrm{g})$ & 2 & 6.67 & Susceptible \\
Vancomycin $(30 \mu \mathrm{g})$ & 0 & 0 & Susceptible \\
Cefoxitin $(30 \mu \mathrm{g})$ & 0 & 0 & Susceptible \\
Ciprofloxacin $(5 \mu \mathrm{g})$ & 29 & 96.67 & Susceptible \\
Gatiflaxacin $(5 \mu \mathrm{g})$ & 29 & 96.67 & Susceptible \\
Ofloxacin $(5 \mu \mathrm{g})$ & 26 & 86.67 & Susceptible \\
Clindamycin $(2 \mu \mathrm{g})$ & 2 & 6.67 & Susceptible \\
Tigecycline $(15 \mu \mathrm{g})$ & 0 & 0 & Susceptible \\
Moxifloxacin $(5 \mu \mathrm{g})$ & 26 & 86.67 & Susceptible \\
Gentamicin $(10 \mu \mathrm{g})$ & 2 & 6.67 & Susceptible \\
Rifampicin $(5 \mu \mathrm{g})$ & 0 & 0 & Susceptible \\
Lomefloxacin $(10 \mu \mathrm{g})$ & 28 & 93.33 & Susceptible \\
Norfloxacin $(10 \mu \mathrm{g})$ & 25 & 83.33 & Susceptible \\
Novobiocin $(30 \mu \mathrm{g})$ & 0 & 0 & Susceptible \\
Teicoplanin $(15 \mu \mathrm{g})$, & 4 & 13.33 & Susceptible \\
Nitrofurantoin $(300 \mu \mathrm{g})$ & 23 & 76.67 & Susceptible \\
Pristinnomycin $(15 \mu \mathrm{g})$ & 26 & 86.67 & Susceptible \\
Ampicillin-Sulbactum $\left(1010 \mu \mathrm{g}^{-1}\right)$ & 14 & 46.67 & Susceptible \\
Piperacillin- Tazobactum $\left(10010 \mu \mathrm{g}^{-1}\right)$ & 0 & 0 & Susceptible \\
\hline
\end{tabular}


resistant to Penicillin, Azithromycin, Ciprofloxacin and Gatiflaxacin, $93.33 \%$ resistant to Lomefloxacin, $86.76 \%$ to Erythromycin, $76.67 \%$ to Nitrofurantoin Clarithromycin, Ofloxacin, Moxiflaxacin, and Pristinnomycin, $83.33 \%$ to Norfloxacin, $46.67 \%$ to Ampicillin- Sulbactum, $13.33 \%$ to Teicoplanin and $6.67 \%$ to Linezolid, Co-Trimoxazole, Clindamycin and Gentamicin, respectively. Almost all the CPS isolates were resistant to at least one antibiotic and many were resistant to multiple antimicrobials (93.33\%) except few isolates. $S$. aureus has developed multidrug resistance worldwide and indicates that as potential hazards to food supply and to human health (Gutiérrez, 2012). These results are in agreement with the previous report wherein the incidence of antibiotic resistance among $S$. aureus strains isolated from different foods showed relatively high incidence rates of resistance to different antibiotics (Vázquez-Sánchez, 2012), whereas Marino et al. (2011) found that the incidence of antibiotic resistance among $S$. aureus strains isolated from food was not remarkably high, excluding Penicillin.

The coa gene, being highly polymorphic because of variable sequences at its $3^{\prime}$ coding region and produces different sizes of amplicon. Similar to the present investigation, Salasaia et al., 2004, Guler et al., 2005 also reported different size of the coa gene from staphylococcal isolates in bovine milk and could be use as specific/ host specific diagnosis of S. aureus infection.

The present study revealed that fish species procured from retail outlets in Gujarat was frequently contaminated with multidrug resistant coagulase positive S.aureus which could possibly be due to poor hygienic profile of the handlers, processing and unhygienic environment of the fish source. Strict hygienic measures are required to reduce the staphylococcal contamination, thereby to provide the wholesomeness of fish.

\section{Acknowledgments}

Authors thank the Director, ICAR- CIFT, Cochin, Kerala for providing necessary facilities and fund to carry out this research work. We duly acknowledge the laboratory work assisted by the technical and supporting staff of the Centre.

\section{References}

Bauer, A.W., W.M.M. Kirby, J.C. Sherris and M. Turck: Antibiotic susceptibility testing by a standardized single disk method. Am. J. Clin. Pathol., 36, 493-496 (1966).

Bhatia, A. and S. Zahoor: Staphylococcus aureus enterotoxins: Areview. J.Clin. Diagnos. Res., 1, 188-197 (2007).

Bujjamma, P. and P. Padmavathi: Prevalence of Staphylococcus aureus in fish samples of local domestic fish market. Int. J. Curr. Microbiol. App. Sci., 4, 427-433 (2015).
Centers for Disease Control and Prevention (CDC): 1600 Clifton Road Atlanta, GA30329-4027,USA(2010).

Chiu, C.H., L.H. Su, C. Chu, J.H. Chia, A.J. Kuo, M.S. Chien and T.Y. Lin: The emergence in Taiwan of fluroquinolone resistance in Salmonella entrica serotype Choleraesuis. N. Engl. J. Med., 346, 413-419 (2002).

CLSI: Performance standards for Antimicrobial susceptibility testing. $24^{\text {th }}$ Supplement, Wayne, Pennsylvania, USA (2014).

Ezzeldeen, N.A., H.A. Mansour and A.A. Ahmed: Phenotypic and molecular identification of Staphylococcus aureus isolated from some Egyptian salted fish. Wor. Appl. Sci. J., 15, 1703-1712 (2011).

FDA: Staphylococcus aureus. In: Bacteriological Analytical Manual. $8^{\text {th }}$ Edn., 10903 New Hampshire Avenue, Silver Spring, MD 20993 (2015).

Guler, I., K. Ok, K. Gunduz, Y. Gulcu and H.H. Hadimli: Antimicrobial susceptibility and coagulase gene typing of Staphylococcus aureus isolated from bovine clinical mastitis in Turkey. J. Dairy Sci., 88, 3149-3154 (2005).

Gutierrez, D., S. Delgado, D.V. Sanchez, B. Martinez, M.L. Cabo, A. Rodriguez, J.J. Herrera and P. Garcia: Incidence of Staphylococcus aureus and analysis of associated bacterial communities on food industry surfaces. Appl. Environ. Microbiol., 78, 8547-8554 (2012).

Jay, J.M.: Modern Food Microbiology. Sixth edition, Aspen Publishers Inc., Gaithersburg, Maryland, USA (2000).

Le-Loir., Baron Y. and F.M. Gautier: Staphylococcus aureus and food poisoning. Genet. Mol. Res., 2, 6376 (2003).

Marino, M., F. Frigo, I. Bartolomeoli and M. Maifreni: Safety-related properties of staphylococci isolated from food and food environments. J. Appl. Microbiol., 110, 550-561 (2011).

Popovic, N.T., A.B. Skukan, P. Dzidara, R. Coz-Rakovac, I. StrunjakPerovic, L. Kozacinski, M. Jadan and D. Brlek-Gorski: Microbiological quality of marketed fresh and frozen seafood caught of the Adriatic coast of Croatia. Vet. Med., 55, 233-241 (2010).

Salasia, S.I.O., Z. Khusnan, C. Lammer and M. Zsch'o'ck: Comparative studies on pheno- and genotypic properties of Staphylococcus aureus isolated from bovine sub-clinical mastitis in Central Java in Indonesia and Hesse in Germany. J. Vet. Sci., 5, 103-109 (2004).

Sergelidis, D., A. Abrahim, T. Papadopoulos, N. Soultos, E. Martziou, V. Koulourida, A. Govaris, A. Pexara, A. Zdragas and A. Papa: Isolation of methicillin-resistant Staphylococcus spp. from readyto-eat fish products. Lett. Appl. Microbiol., 59, 500-506 (2014).

Shittu, A., J. Lin and D. Kolawole: Antimicrobial susceptibility patterns of S. aureus and characterization of MRSA in southwestern Nigeria. Wounds., 18, 77-84 (2006).

Simon, S.S. and S. Sanjeev: Prevalence of enterotoxigenic Staphylococcus aureus in fishery products and fish processing factory workers. Food Control, 18, 1565-1568 (2007).

Vazquez-Sanchez, D., M. Lopez-Cabo, P. Saa-lbusquiza and J.J.R. Herrera: Incidence and characterization of Staphylococcus aureus in fishery products marketed in Galicia (Northwest Spain). Int. J. Food Microbiol., 157, 286-296 (2012).

World Health Organisation (WHO): Global public health security in the $21^{\text {st }}$ century Geneva. In: The World Health Report, WHO, Geneva (2007). 